UCRL-ID-122254

\title{
PROTOCOLS OF RADIOCONTAMINANT AIR MONITORING FOR INHALATION EXPOSURE ESTIMATES
}

Joseph H. Shinn, PhD

Health And Ecological Assessment Division

Lawrence Livermore National Laboratory

September 1995

Work performed under the auspices of the U.S. Department of Energy at Lawrence Livermore National Laboratory under contract W-7405-Eng-48. 


\section{DISCLAIMER}

This report was prepared as an account of work sponsored by an agency of the United States Government. Neither the United States Government nor any agency thereof, nor any of their employees, make any warranty, express or implied, or assumes any legal liability or responsibility for the accuracy, completeness, or usefulness of any information, apparatus, product, or process disclosed, or represents that its use would not infringe privately owned rights. Reference herein to any specific commercial product, process, or service by trade name, trademark, manufacturer, or otherwise does not necessarily constitute or imply its endorsement, recommendation, or favoring by the United States Government or any agency thereof. The views and opinions of authors expressed herein do not necessar. ily state or reflect those of the United States Government or any agency thereof. 


\section{DISCLAIMER}

Portions of this document may be illegible electronic image products. Images are produced from the best available original document. 


\section{Table of Contents}

List of Figures................................................................................................................................

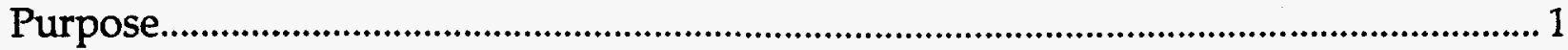

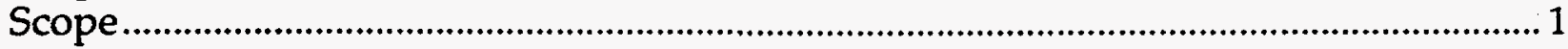

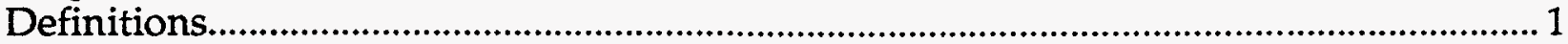

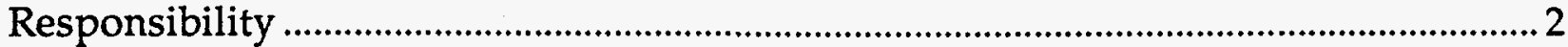

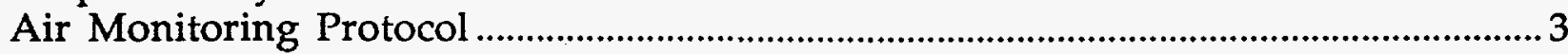

Air Sampling Required in Resuspension Monitoring...............................................

Soil Sampling for Radioactive Resuspension Sources.............................................

Analytical Methods for Aerosols And Soils .............................................................4

Complementary Meteorological Measurements...........................................................4

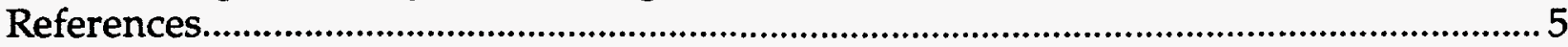

Appendices A-E: Detailed Procedures For Monitoring Radiocontaminants In Air.6

Summary ...................................................................................................................6

Appendix A-Detailed Procedure For Operating High Volume and Cascade Impactor Ambient-Air Particle Samplers ………........................................................... A-7

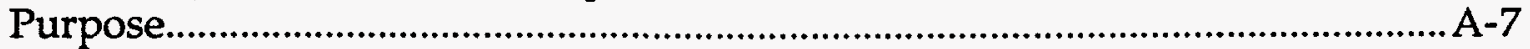

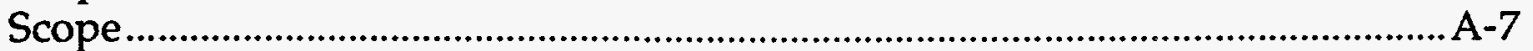

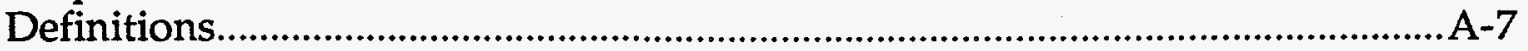

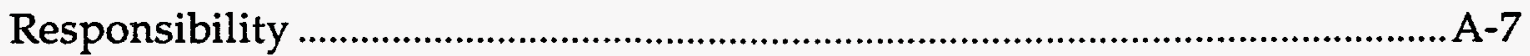

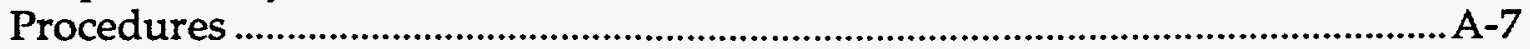

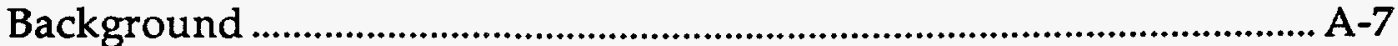

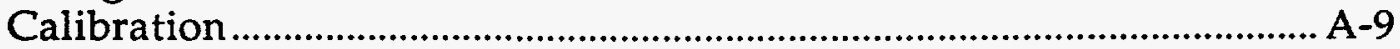

Cascade Impactor Operation .................................................................... A-10

High Volume Sampler Operation ........................................................... A-11

Appendix B-Detailed Procedure For Setting Up Vertical-Array Air Samplers

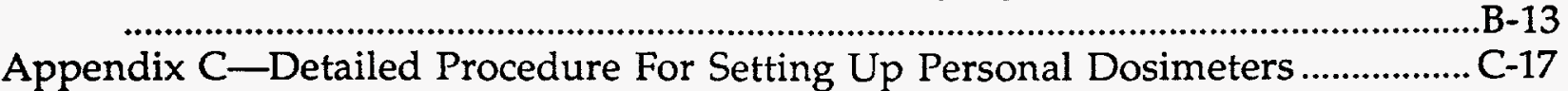

Appendix D-Detailed Procedure For Weighing And Handling Air Samples

Collected On Filters By Impaction.............................................................................. D-18

Appendix E-Detailed Procedure For Setting Up An Automatic Energy-Budget

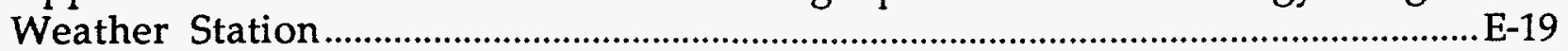

\section{List of Figures}

Figure 1. Side view of vertical-array air sampler...................................................... B-14

Figure 2. Top view of vertical-array air sampler....................................................... B-15

Figure 3. Exploded view of internal components of verital-array air sampler...... B-16 


\section{Purpose}

Monitoring the plutonium and americium particle emissions from soils contaminated during atmospheric nuclear testing or due to accidental releases is important for several reasons. First, it is important to quantify the extent of potential human exposure from inhalation of alpha- emitting particles, which is the major exposure pathway from transuranic radionuclides. Second, the information provided by resuspension monitoring is the basis of criteria that determine the target soil concentrations for management and cleanup of contaminated soil sites. There are other radioactive aerosols, such as the fission products (cesium and strontium) and neutron-activation products (europium isotopes), which may be resuspended and therefore necessary to monitor as well.

This Standard Protocol (SP) provides the method used for radiocontaminant air monitoring by the Health and Ecological Assessment Division (formerly Environmental Sciences Division), Lawrence Livermore National Laboratory, as developed and tested at Nevada Test Site (NTS) and in the Marshall Islands.

The objective of this SP is to document the applications and methods of monitoring of all the relevant variables. This protocol deals only with measuring air concentrations of radionuclides and total suspended particulates (TSP, or "dust"). A separate protocol presents the more difficult measurements required to determine transuranic aerosol emission rates, or "resuspension rate".

\section{Scope}

This SP covers the methods of measurement of the site-specific transuranic radionuclide air monitoring variables: concentration in air, soil concentration, and relevant meteorological measurements. (A separate protocol covers the calculation and measurement of resuspension factor, resuspension rate, activity coefficient, enhancement factor, median aerodynamic diameter, and particle geometric standard deviation.)

\section{Definitions}

The terms used in this SP are the same as those originated in the reference: "Resuspension and Redistribution of Plutonium in Soils", by L.R. Anspaugh, J.H. Shinn, P.L. Phelps, and N.C. Kennedy, Health Physics, V29, 571-582, 1975. The terms and definitions are consistent with those of U. S. Environmental Protection Agency in its considerations of proposed guidance in 1977, and terms and definitions in the review by (J.W. Healy, 1980).

CONCENTRATION IN AIR is the time-integrated determination (usually over several days) of isotope activity per unit volume of air or of dust mass per unit volume of air. Units are Bq per cubic meter or micrograms of TSP per cubic meter. 
INTEGRATED SOIL CONCENTRATION is the isotope radioactivity per unit mass of soil, integrated over depth and divided by the mean bulk density of soil; units are Bq per meter squared. This is also referred to as "deposition".

RESUSPENSION FACTOR is the isotope-specific air concentration divided by the local isotope-specific integrated soil concentration; units are inverse length in meters.

RESUSPENSION RATE is the local isotope emission flux (Bq per meter square ground area per day) divided by the local integrated soil concentration (Bq per meter squared) to obtain the fraction of the integrated soil concentration suspended per day.

ACTIVITY COEFFICIENT is the isotope-specific radioactivity per mass (Bq/gram); it applies to either the soil particles or the aerosols.

ENHANCEMENT FACTOR is the ratio of activity coefficient of the aerosols to that of local soil; it is not particle-size specific even though there is large disparity between aerosol size and soil particle-size. It is dimensionless.

MEDIAN AERODYNAMIC DIAMETER is the geometric mean diameter of the suspended particle-size distribution (the first parameter of the usually-observed lognormal frequency distribution). Units are given in micrometers.

PARTICLE GEOMETRIC STANDARD DEVIATION is the second parameter to define the lognormal distribution of particle-size (dimensionless).

\section{Responsibility}

The principal investigator (PI) for resuspension monitoring shall be responsible for the proper conduct of this procedure. The PI will assure that all measurements and calculations are obtained to satisfy the above defined terms and their applications. The PI will provide for training and for certification of assistants, quality assurance and calibration programs, documentation of intermediate and final data analyses, documentation of transuranic analysis results, and documentation of data interpretation. The PI will have graduate training in the related sciences (meteorology, health physics) and experience in the measurement techniques required in this SP. At least one assistant will have experience in electronics sufficient to operate and maintain weather stations and in situ gamma-spectroscopy equipment. 


\section{Air Monitoring Protocol}

The following summary describes the procedures by category.

\section{Air Sampling Required in Resuspension Monitoring}

Four types of air samplers are required--(1) high-volume (HV) air samplers for air concentration, (2) cascade impactors (CI) for the aerosol particle-size distribution, (3) vertical sample array (VSA) air samplers used at four heights above ground simultaneously and (4) personal dosimeter (PD) air samplers for determination of the potential human exposures in the local area of contamination. Detailed Procedures (DP) are provided herein for their use.

At all field sites the DETAILED PROCEDURE FOR OPERATING HIGH VOLUME AND CASCADE IMPACTORS will be the guideline followed. The VSA air samplers are used to measure the vertical gradient of radioactivity in the air-layer two meters above the soil. At all field sites the DETAILED PROCEDURE FOR OPERATING VERTICAL ARRAY AIR SAMPLERS will be the guideline followed. All $\mathrm{HV}, \mathrm{CI}$, and VSA filters will be prepared according to the DETAILED PROCEDURE FOR WEIGHING AND HANDLING AIR SAMPLES COLLECTED ON FILTERS BY IMPACTION.

Two simultaneous HV or CI and two VSA (four samplers per VSA) will be operated. The exposure time will be long enough (one to two weeks) to be sufficient to obtain enough aerosol to exceed ten times the minimum detectability for the background isotope or TSP concentration. Preliminary trials will be conducted to establish detectability; an estimate can be made from the known soil contamination levels and comparison to the results of previously published studies. Precision of flow measurement and elapsed time will be $10 \%$ or better and calibration of each $\mathrm{HV}, \mathrm{CI}$, and VSA unit will be made in the field by a manometer (5\% precision) with the aid of the predetermined calibration equation specified by the referenced DP.

When there is the opportunity to evaluate a potential human exposure the personal dosimeters (PD) will be used on volunteers who are assisting in the study. At such opportunities, the DETAILED PROCEDURE FOR OPERATING PERSONAL DOSIMETERS will be the guideline followed. For example, an opportunity arose during the Cleanup and Treatment Trials in Area 11 of NTS, when vacuum-truck drivers and operators wore PD in addition to respirators that were used during operations (See Shinn et al, 1989).

\section{Soil Sampling for Radioactive Resuspension Sources}

The method of in-situ gamma measurement using the FIDLER (Field Instrument for Detection of Low Energy Radiation) is to be used for Am-241 in surface soil, because it is a spatially-integrating technique most representative of the source of aerosols measured by an air sampler. The references, Patton, S.E., DETAILED PROCEDURE FOR FIDLER SET-UP AND CALIBRATION, DETAILED PROCEDURE 
FOR FIDLER IN-SITU MEASUREMENTS, and DETAILED PROCEDURE FOR FIDLER DATA ANALYSIS, will be the guidelines followed. In addition, soil samples are required.

The ratio of other transuranic isotopes (Pu-239-240, $\mathrm{Pu}-238$, and others) to Am-241 must be determined and the vertical distribution of Am-241 in the top 8-cm of soil must be determined in order to calculate the activity coefficients, enhancement factors, integrated soil concentrations, resuspension factor, and resuspension rate for those isotopes. These measurements are also available from other studies, but are necessary to confirm by taking $2.5-\mathrm{cm}$ surface samples pooled along a given transect near the resuspension site. The sampling will follow the reference protocols. Unless specified elsewhere, use the protocol previously used by Wireman, D.L. and H.J. Kayuha, STANDARD NEVADA APPLIED ECOLOGY GROUP (NAEG) PROCEDURES FOR PREPARATION OF SOIL SAMPLES FROM NAEG INTENSIVE STUDY AREAS, except a 10-mesh sieve is used in place of the 100-mesh sieve specified.

\section{Analytical Methods for Aerosols And Soils}

The method of gamma spectroscopy for determination of Am-241 on the air filters or soil samples will be used because of its lower cost and high throughput for a large number of samples. The LLNL methodology for gamma spectroscopy will be followed. If the level of Am-241 is too low in the samples $(<0.4 \mathrm{~Bq} / \mathrm{sample})$, a special chemical method must be used as discussed below.

Special chemical methods are required to determine the ratios of $\mathrm{Am}-241$ and $\mathrm{Pu}-$ isotopes on air filters and soil samples. This is attempted only when considerable exposure of air filters to dust has occurred and the activity coefficient of the dust is suspected to be high. It is not possible, for example, on the PD filters. The LLNL methodology for alpha radiochemistry of air filters and soil samples will be followed. The minimum detection limit (MDA) is $0.005 \mathrm{~Bq}$ per sample, which is sufficient for background Pu-aerosol concentrations by $\mathrm{HV}$ in one week. Also, the analysis precision is $0.005 \mathrm{~Bq}$ per sample. Analysis will be quality assured by a quality control program with duplicate filters, blanks, and spiked filters in addition to the quality control analysis.

\section{Complementary Meteorological Measurements}

Complementary meterological measurements are used (Shinn et al, 1989) to determine relevant weather data at any time during the period of measurement of concentration in air. This is done with an automatic weather station which measures continuously the wind speed, wind direction, and energy budget components of radiant energy. See the DETAILED PROCEDURE FOR SETTING UP AN AUTOMATIC ENERGY-BUDGET WEATHER STATION. 


\section{References}

Anspaugh, L.R., J.H. Shinn, P.L. Phelps, and N.C. Kennedy (1975), "Resuspension and Redistribution of Plutonium in Soils," Health Physics, V29, 571-582.

Healy, J.W., Review of Resuspension Models (1980), Transuranic Elements in the Environment, U.S. Department of Energy Technical Information Center, DOE/TIC22800, (edited by W.C. Hanson), pp209-235.

Patton, S.E. (1990), BECAMP Quality Assurance Detailed Procedure for FIDLER Data Analysis, HEA Division, Lawrence Livermore National Laboratory, Livermore, CA, BECAMP-DP-403, RO.

Patton, S.E. (1990), BECAMP Quality Assurance Detailed Procedure for FIDLER InSitu Measurements, HEA Division, Lawrence Livermore National Laboratory, Livermore, CA, BECAMP-DP-402, RO.

Patton, S.E. (1990), BECAMP Quality Assurance Detailed Procedure for FIDLER Setup and Calibration, HEA Division, Lawrence Livermore National Laboratory, Livermore, CA, BECAMP-DP-401, RO.

Shinn, J.H., E.H. Essington, F.L. Miller, Jr., T.P. O'Farrell, J.A. Orcutt, E.M. Romney, J.W. Shugart, and E.R. Sorom (1989), "Results of a Cleanup and Treatment Test at the Nevada Test Site: Evaluation of Vacuum Removal of Pu-Contaminated Soil," Health Physics, V57(5): 771-779.

Wireman, D.L., and H.J. Kayuha (1976), "Standard Nevada Applied Ecology Group (NAEG) Procedures for Preparation of Soil Samples From NAEG Intensive Study Areas," in White, M.G. and Dunaway, P.B. (editors), Nevada Applied Ecology Group Procedures Handbook For Environmental Transuranics, Report NVO-166, Vol. 1, ERDA (U.S. Department of Energy) Nevada Operations Office, Las Vegas, NV, pp21-28. 


\section{Appendices A-E}

\section{Detailed Procedures For Monitoring Radiocontaminants In Air}

\section{Summary}

This compendium provides detailed procedures used collectively to measure the concentration of aerosols, in particular TSP (dust concentrations) and the concentrations of radionuclides in air which are resuspended by wind. Any complete investigation must be covered in a separate Standard Protocol. 


\section{Appendix A-Detailed Procedure For Operating High Volume And Cascade Impactor Ambient-Air Particle Samplers}

\section{Purpose}

The following procedure (DP) is the standard method used to collect aerosols by High Volume (HV) air samplers to measure air concentration and by Cascade Impactors (CI) to measure particle size-distribution.

\section{Scope}

This DP describes the methods of set-up, calibration, and filter media loading associated with field operations for air sampling.

\section{Definitions}

HV is the HIGH VOLUME air sampler, in particular Model GMWL-2000, with filter holder Model FH-2100 and aluminum shelter Model GMW- 8500 manufactured by General Metal Works Inc., 8368 Bridgetown Road, Village of Cleves, OH 45002.

CI is the CASCADE IMPACTOR air sampler, in particular Model 65-000, manufactured by Anderson Air Samplers 2000 Inc., P.O. Box 20769, 2000 Sullivan Road, Atlanta, GA 30320. This sampler mounts on top of a backup filter in the Model GMWL-2000 HV as defined above.

MANOMETER is a U-tube manometer filled with water or dyed-water and range 015 inches of water. The dial-type manometer that may be substituted if calibrated, is Magnehelic, Models $2002 \mathrm{C}$ or 2005C, (0-2 inches and 0-5 inches of water respectively), Dwyer Instruments Inc., Michigan City, IN.

\section{Responsibility}

The principal investigator (Dr. Joseph H. Shinn, or alternatively, Dr. William Robison) and the lead technical coordinator (Cleo O. Fry) will be responsible for onthe-job training to operate the HV and CI. Those trained are Scott Patton, Frank Gouveia, and James Stephen Johnson of LLNL.

\section{Procedures}

\section{Background}

The HV samplers use 8- $x$ 10-inch fiber filters, either Gelman (type AE) glass fiber or Wattman 41 cellulose fiber. The cellulose fiber is preferred to reduce the effort required for acid dissolution after filter exposure. Flow rates on the HV are to be nominally 68 cubic meters per hour $(40 \mathrm{cfm})$, and monitored at a pressure tap on the blower at least twice during operation of the HV, at startup and conclusion of the exposure. The lapsed time of operation must be measured for each $\mathrm{HV}$ by either a 
pressure-activated clock or by an electronic timer on the motor. Refer to the OPERATORS MANUAL, GMW High Volume Air Samplers, General Metal Works Inc., Model GMWL-2000 Air Sampling System. This model has been superseded in recent years, but the procedure described here applies to the older model in our inventory.

Different models and manufacturers vary as to the location of the pressure tap. In this DP the discussion refers to the GMW Model GMWL-2000 motor-housing with a pressure tap on the bottom of the housing. The bottom is a metal plate with 11 onehalf-inch diameter holes to dissipate the exhaust. The pressure is thus positive with respect to outside air. In principle, other models and manufacturers may be substituted with proper calibrations and a revised calibration equation. Pressure may be measured by any portable manometer having at least $5 \%$ precision over the range of pressure from 0.5 to 5 inches of water.

Cascade Impactors (CI) are the jet-plate type, five-stage Anderson model 65-000 (five circular, flat metal plates) operated at 34 cubic meters per hour $(20 \mathrm{cfm})$ and monitored as are the HV. Cellulose (Wattman 41) or glass (Gelman type AE) fiber filters will be used on the $\mathrm{CI}$ to minimize bounce-off. The same motors which power the HV may be use on the CI, but run at slower speed to achieve the specified flow. In this DP we refer to the GMW models again with the pressure tap on the bottom and a perforated bottom plate; but we plug 5 of the ll holes when the motor is used on $\mathrm{CI}$ for the sheer convenience of being able to use the same manometer and nearly the same pressure setting as used for the HV. This device does not interfere with the performance but requires a different calibration equation for the CI. One-half-inch diameter snap-in butch plugs are used to block the holes; in an emergency, plastic tape or duct tape may be used temporarily.

The modified and sealed vacuum-cleaner motors which are used to operate the HV and CI will be maintained to operate unattended for at least two weeks. Unless brushless motors are used this means that the commutators must be smooth, the brushes replaced every two weeks, and motors given a break-in period at slow speed. The speed of the motors will be set at the beginning of each exposure period by means of a variable autotransformer, such as a VARIAC. Automatic speed controls during the exposure period are optional unless the air is extremely dusty; in any case the flow rate must be monitored at the pressure tap as stated above. We have found that in "clean" rural air, weekly pressure measurements are sufficient to correct for flow rates which have declined due to dust loading. The correction factor will be a linear average of the flow rate over the duration of the filter exposure time. The CI will not operate correctly if there is a substantial deviation in the prescribed flow rate; this condition must be noted in the log-book when the filters are removed. "Dirty" air (loading greater than 35 micrograms per cubic meter) requires that an automatic speed control must be used on the CI. The speed control to be used is the General Motor Works G360, volumetric flow controller (VFC), which is a critical orifice that is not greatly affected by changes in filter loading. When placed between the filter holder and the blower motor it maintains the flow at the design rating. A 
special order G360 is necessary to meet the 34 cubic meters per hour ( $20 \mathrm{cfm}$ ) rating required.

\section{Calibration}

The following calibration procedure is adapted from the manufacturer's instructions for the Model GMW-25 calibrating orifice assembly, Serial Number W71, which is traceable to NIST standards, and which is compared annually to a standard positive displacement rotary type meter by the LLNL Principal Investigator.

1. Assemble the GMWL-2000 HV Air Sampler with a motor that has been run for a break-in period (after new brushes are installed the motor should be run for an 8hour period at about $30 \%$ of full speed).

2. Connect a Magnehelic manometer to the pressure tap at the exhaust end of the motor/blower $(\mathrm{M} / \mathrm{B})$ unit using a length of tubing.

3. Plug sampler into a variable autotransformer (VARIAC: Model 3PN116B, Superior Electric Co., or Model 3PN1010, Staco Energy Products). Plug the VARIAC into $115 \mathrm{VAC}, 60 \mathrm{~Hz}$, power source.

4. Remove the filter holder from the motor/blower unit.

5. Replace the filter holder with the GMW-25 orifice calibrator using the Number 18 Resistance Plate supplied with the calibrator.

6. Connect a water manometer or Magnehelic manometer to the pressure tap of the calibration oriface.

7. Turn the power on and adjust the VARIAC to maximum power.

8. Read the manometer pressure on the orifice calibrator in inches of water and convert to actual flow rate using the curve supplied with the GMW-25. Read the pressure on the manometer at the pressure tap on the motor/blower (M/B) unit. Record the actual rate and the M/B pressure on a data sheet.

9. Reduce the flow rate either by changing the supplied resistance plates or by adjusting the VARIAC, recording the actual flow and the $M / B$ pressure until five or more data pairs are available.

10. Using the readings established with the above procedure, plot a curve which represents the actual flow rate versus the $M / B$ readings. To assist in the curve fitting, do a linear regression with the actual flow as the independent variable and the square root of $\mathrm{M} / \mathrm{B}$ pressure as the dependent variable. Record the statistics of fit.

After many years of experience, we have found two general equations, which apply to all $\mathrm{HV}$ or $\mathrm{CI}$ when operating properly as follows. The calibration for flow F (cubic 
meters per hour) is proportional to the square root of pressure $\mathrm{P}$ (inches of water) with coefficient of variation 0.08 for both the $\mathrm{HV}$ and CI motors:

For the HV (no holes blocked)

$\mathrm{F}=68 \sqrt{ }(\mathrm{P} \bullet \mathrm{A})$

For the CI (six of eleven holes blocked)

$\mathrm{F}=32 \sqrt{ }(\mathrm{P} \bullet \mathrm{A})$

Where $\mathrm{A}$ is an altitude correction factor ( $\mathrm{A}=1$ at sea level). At the rated flow, $\mathrm{P}$ will decrease about $3.3 \%$ for every 1000 feet increase in altitude; the correction factor $A=$ $(1+0.000033 \mathrm{Z})$ for the altitude $\mathrm{Z}$ in feet.

All motors will be calibrated after maintenance to assure that they fall within the expected relative deviation of 0.08 from the measured flow at the desired pressure setting. At sea level, a pressure of 1.0 inch of water yields for the HV the desired flow of 68 cubic meters per hour $(40 \mathrm{cfm})$. A pressure setting of 1.13 inches of water yields for the $\mathrm{CI}$ the desired flow of 34 cubic meters per hour $(20 \mathrm{cfm})$. When the HV and $\mathrm{CI}$ are operated at an altitude of 6000 feet, however, the correct pressure setting is reduced by a factor of 0.91 ( 0.91 inch for the HV and 1.03 inch for the $\mathrm{CI}$ ).

\section{Cascade Impactor Operation}

The following instructions are to be utilized to interface the CI (Model 65-000, Anderson 2000 Inc.) to the HV (Model GMWL-2000, General Metal Works Inc.) and to operate the $\mathrm{CI}$.

Loading of the $\mathrm{CI}$ with filter media and preparing the $\mathrm{CI}$ assembly cannot be done properly without the aid of the manufacturers instructions (see INSTRUCTIONS FOR OPERATION OF THE HI-VOLUME SAMPLER HEAD, MODEL 65-000.

1. Load the Model 65-000 Cascade Impactor (CI) with filter media according to the instructions, and place in a clean plastic bag.

2. Follow the instructions for operating the High Volume (HV) sampler GMWL2000 , until at the stage of securing the face plate. Use a motor/blower $(\mathrm{M} / \mathrm{B})$, however, that has 5 of the 11 holes blocked on the bottom of the motor where the air exhausts.

3. Remove the $\mathrm{CI}$ assembly from the plastic bag. In place of the face plate on the GMWL-2000, secure the CI assembly to the slots in the CI interface adapter plate, using the four wing nuts which normally hold the HV face plate.

4. Follow the remaining instructions for operating the High Volume (HV) sampler GMWL-2000, except the speed of the motor should be set with the VARIAC to reach 
the required flow rate of 34 cubic meters per hour $(20 \mathrm{cfm})$ as indicated by the manometer on the $\mathrm{M} / \mathrm{B}$.

\section{High Volume Sampler Operation}

The following list is adapted from the manufacturer's instructions for the HV Model GMWL-2000.

1. Assemble the GMWL-2000 HV Air Sampler with a motor that has been run for a break-in period (after new brushes are installed the motor should be run for an 8hour period at about $30 \%$ of full speed).

2. Place sampler and filter holder in the servicing position by raising both the sampler motor/blower (M/B) unit and filter holder up until the filter holder is above the top level of the shelter. Then rotate the unit one-quarter turn so that the filter holder hangs in the rectangular hole in the sampler support pan.

3. Remove faceplate by loosening the four wing nuts allowing the swing bolts to swing down out of the way.

4. Carefully center a new filter, rougher side up, on the supporting screen. Properly align the filter on the screen so that when the faceplate is in position the gasket will form an airtight seal on the outer edges of the filter.

5. Secure the filter with the faceplate and four brass wing bolts with sufficient pressure to avoid air leakage at the edges.

6. Rotate and lower the filter holder and $\mathrm{M} / \mathrm{B}$ assembly to its normal operating position.

7. Wipe clean the area around the filter holder with ethanol and a clean cloth. Close lid carefully and secure catch.

8. Plug sampler into a variable autotransformer (VARIAC: Model 3PN116B, Superior Electric Co., or Model 3PN1010, Staco Energy Products). Plug the VARIAC into $115 \mathrm{VAC}, 60 \mathrm{~Hz}$, power source.

9. Connect a Magnehelic manometer to the pressure tap at the exhaust end of the motor/blower $(\mathrm{M} / \mathrm{B})$ unit using a length of tubing. Zero the Magnehelic by removing the tubing and adjusting the screw on the face while holding the Magnehelic horizontal; reconnect the tubing.

10. Turn the power on and adjust the VARIAC to set the motor speed, using the Magnehelic to measure the desired pressure (about 1.0 inch of water for 68 cubic meters per hour at sea level pressure, or more precisely according to a specific calibration curve corrected for altitude). Record the time of start. 
11. Flow measurements are taken at the beginning and end of the sampling period. Disconnect the Magnehelic during the sampling period.

12. After the sampling period, disconnect the $M / B$ unit from the power source; place the sampler in the servicing position and remove the face plate to expose the filter. Record the ending time.

13. Carefully remove the exposed filter from the supporting screen by holding it gently at the ends (not at the corners). Fold the filter lengthwise so that sample touches sample, and place it in a clean plastic bag. The serial number on the filter should show through the bag; the bag should also be labeled with the number. 


\section{Appendix B-Detailed Procedure For Setting Up Vertical-Array Air Samplers}

The array samplers consist of four circular, cellulose, $89-\mathrm{mm}$ filters mounted on a metal screen inside inverted plastic funnels. They are arrayed in vertical profile, one each at $0.25 \mathrm{~m}, 0.50 \mathrm{~m}, 1.0 \mathrm{~m}$, and $2.0 \mathrm{~m}$ above ground. Each must have identical flow rates, so a special head with four outlets of $2-\mathrm{cm}$ internal diameter has been fabricated to fit on a standard HV motor. Equal lengths of large-diameter plastic tubing connect each outlet to a filter assembly. Air speed through the filter assembly is set with a variable transformer to flow at nominally 10 cubic meters per hour through each filter. After leak-testing the assembly, calibration is done in the field with a manometer and the same protocol for maintenance and for recording time and flow rates is used as for the HV and CI. The variable transformer (for example, a VARIAC; Model 3PN116B, Superior Electric Co., or Model 3PN1010, Staco Energy Products) is set first and the flow rate is measured at each of the four filter assemblies and checked periodically.

The design of the vertical-array filter assembly is shown on the attached figures. In addition, it has been found necessary to cut a piece of aluminum sheet metal, 3.3 inches by $1 \mathrm{inch}$, and stand it inside the funnel beneath the metal screen to keep the filter and screen from bowing inward due to the partial vacuum. The plastic funnel is inverted when mounted on the mast and care is taken not to kink any of the large-diameter plastic tubing. The 1.2-inch-diameter end of the plastic funnel is tapered slightly so that it slides snugly into a standard plastic pipe. This facilitates easy removal and calibration of each filter assembly. For calibration, a 1.2-inchdiameter critical orifice is temporarily inserted between the filter assembly and the standard plastic pipe. This critical orifice has a hose-barb pressure tap and a manometer attached (Magnehelic, 0-25 inches of water) and is a transfer standard; it is calibrated against the Model GMW-25 calibrating orifice assembly, Serial Number W71, which is traceable to NIST standards. The calibration for flow F (cubic meters per hour) is proportional to the square root of pressure $P$ (inches of water) with standard error 0.22 cubic meters per hour: Figures 1-3 show the side, top and expanded view of a vertical-array air sampler, respectively. 


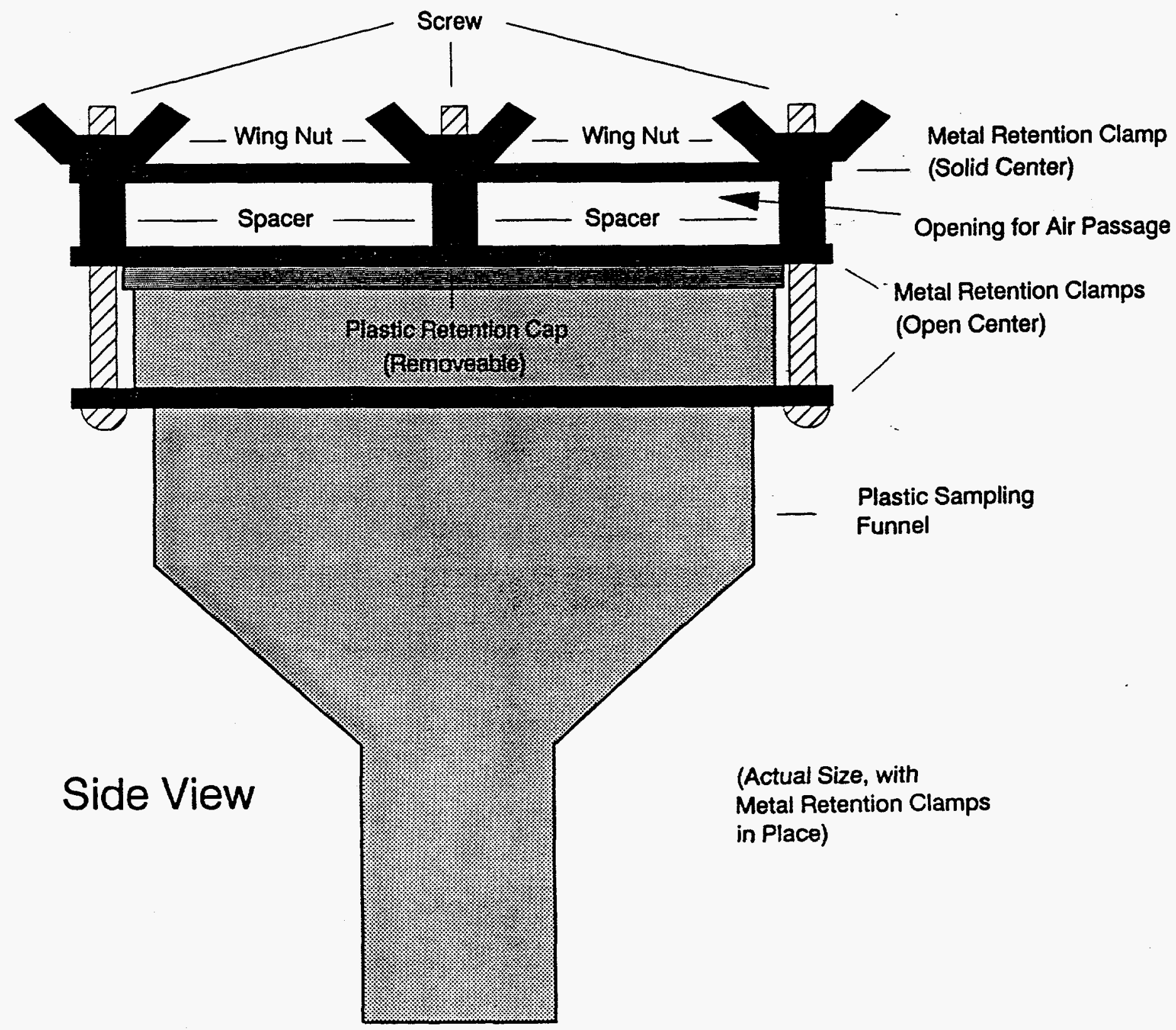

Figure 1. Side view of vertical-array air sampler. 


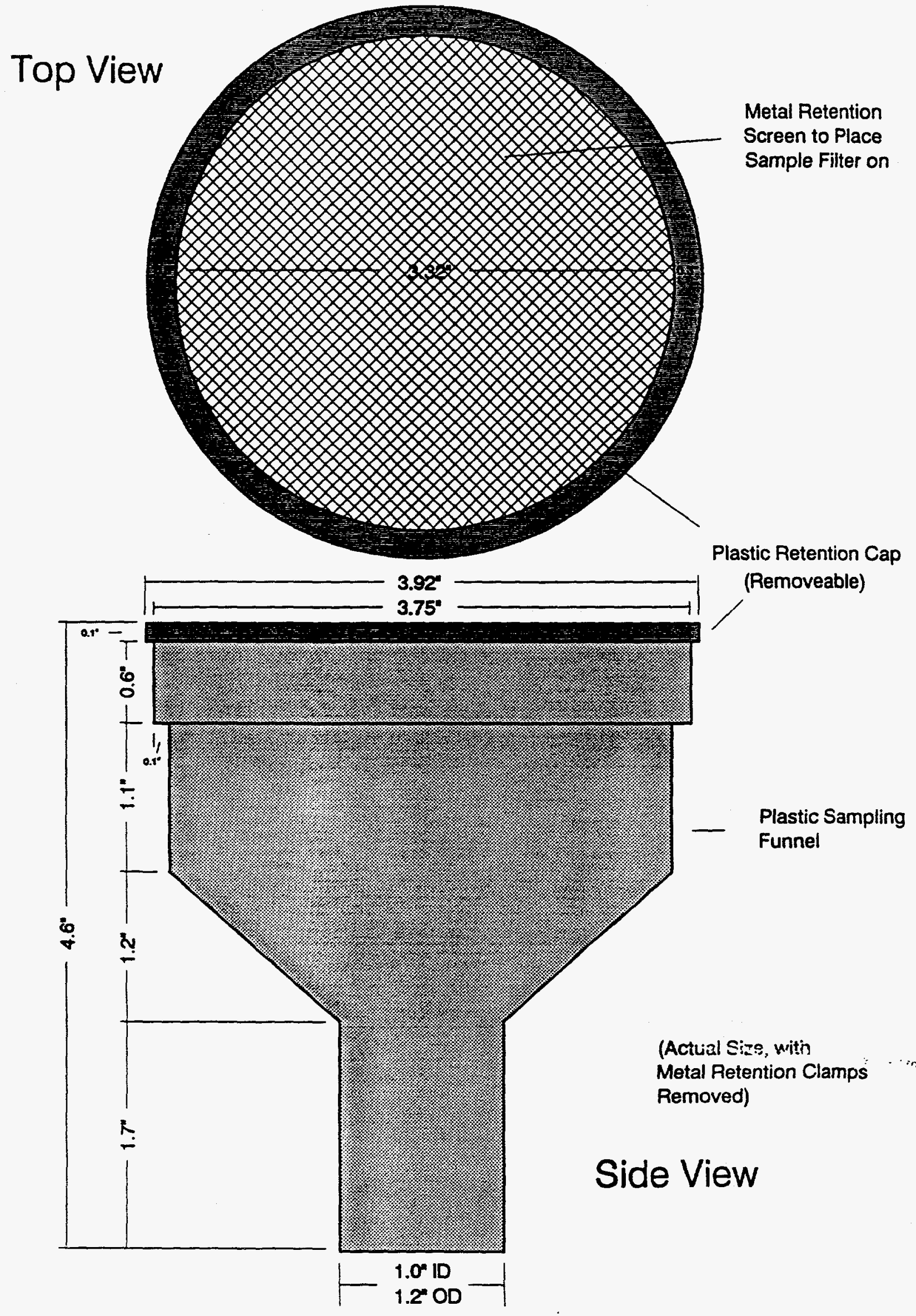

Figure 2. Top view of vertical-array air sampler.

B-15 


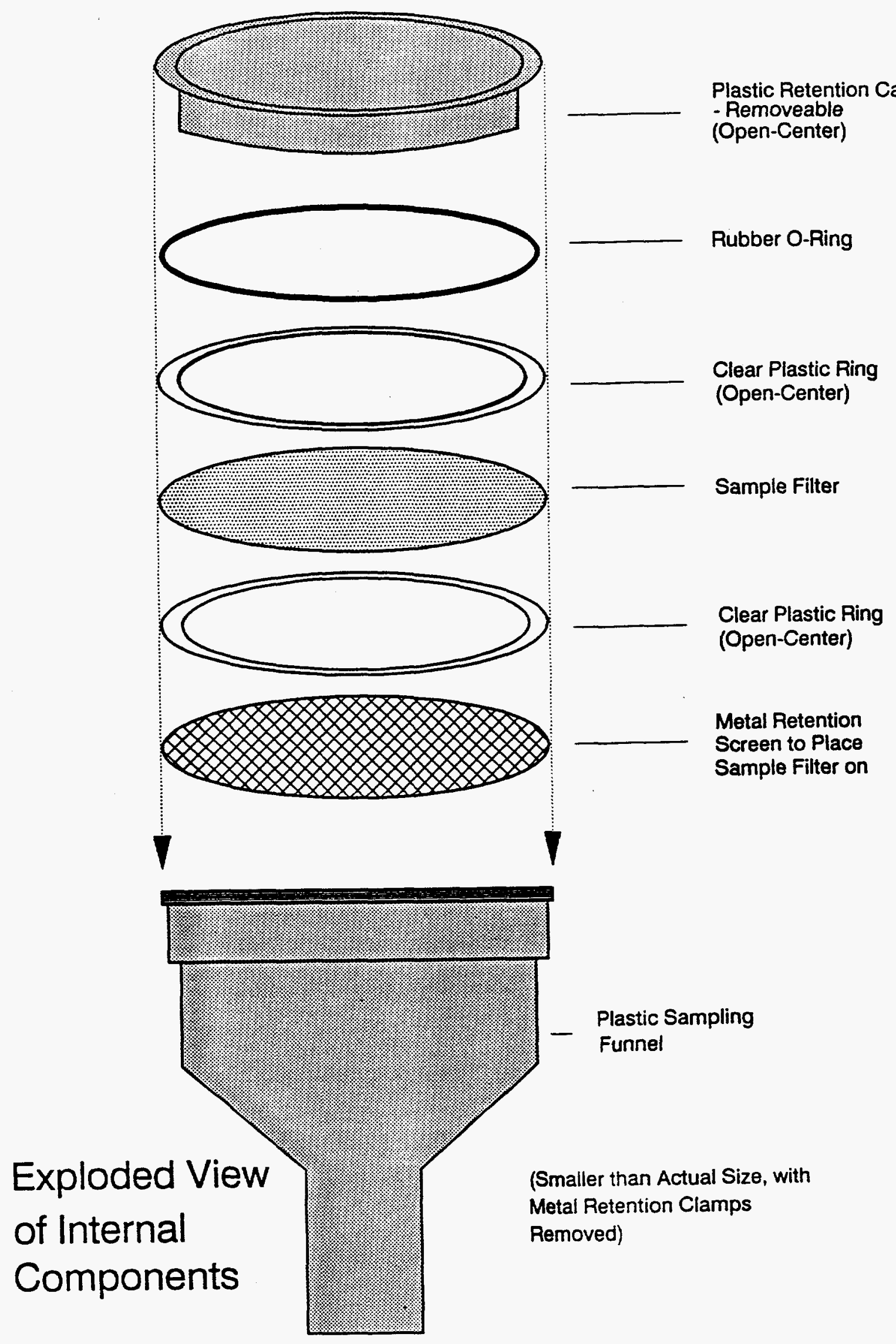

Figure 3. Exploded view of internal components of verital-array air sampler. B-16 


\section{Appendix C-Detailed Procedure For Setting Up Personal Dosimeters}

Various PD are acceptable, providing the particle-size cutoff is known and that a maximum flow rate is available. Each PD must be supplied with a rechargeable battery pack. The PD used are MSA (Mine Safety Appliance Co., Model S Monitaire) and consist of filter holders mounted on standard nylon cyclones for large particle separation. The MSA units are driven by battery-operated portable pumps at a flow rate of 0.1 cubic meter $/ \mathrm{h}(0.06 \mathrm{cfm})$. The PD should use $37-\mathrm{mm}$ fiber filters such as teflon (Millipore Corporation, type Fluoropore FA). Flow rates should be set in the laboratory, but checked in the field prior to and following exposure using a certified venturi. A log of each PD giving the application, off- and on-times, and flow rates is necessary since it might be a mobile application, or workers may go on and off the contamination site. For maintenance and operation of the MSA PD, the manufacturer's manual is followed exactly. The PD filters are extremely difficult to weigh with any precision. 


\section{Appendix D-Detailed Procedure For Weighing And Handling Air Samples Collected On Filters By Impaction.}

All filters will be weighed before and after exposure in a room with regulated temperature and humidity. Filters must be allowed sufficient time to adjust to the weigh room environment, normally $12 \mathrm{~h}$ if the filters are spread-open on a perforated shelf. The filters must be given an identification number (ID) prior to first weighing and must be entered into a $\log$ as soon as given the ID. A chain-ofcustody requirement begins at this time, with the transfer of each filter from weighing room to field and back being dated and signed each time by the appropriate technician. After the final weighing the filters will be sealed in the container appropriate for the transuranic analytic procedure or gamma facility. The ID will be written on the container and a chain-of- custody record sent with the sample to the analytic or gamma facility. In some cases more than one filter may be enclosed in the container when the aerosol activity levels are low; in this case a new ID will be issued and the identification record will show this merger. The precision of weighing will be 10 micrograms for the $\mathrm{HV}, \mathrm{CI}$, and array filters, and will be 1 microgram for the PD filters. These precisions require the use of rubber gloves for handling the filters, plastic bags for transporting the filters, and precautions with the balance to avoid room air drafts, and other sources of error. Reference weights for balance calibration will be used at all times. 


\section{Appendix E-Detailed Procedure For Setting Up An Automatic Energy-Budget Weather Station}

The automatic energy-budget weather station will have at a minimum the wind speed and direction at $2 \mathrm{~m}$ height, and the temperature to $0.1 \mathrm{C}$ at two heights (e.g. $0.25 \mathrm{~m}$ and $2 \mathrm{~m}$ ). Various manufacturers, such as Handar, Inc, Model $540 \mathrm{DCP}$, or Campbell Scientific, Model 21MX are used as the base station. Calibrated thermisters in self-aspirated thermal shield, and Met One, Inc, wind sensors are normally used. Additional data that may be collected are the lateral turbulence intensity determined by the standard deviation of the wind vane fluctuations, and the sensible heat flux determined by the energy budget technique. The energy budget technique uses a standard Fritschen-type net radiometer, one or more soil heat flux plates buried a few centimeters below the surface, and an independent method to measure water vapor flux. When operating at any site during the rainy season, a tipping-bucket rain gage will be installed. 